\title{
Adrenocortical Steroidogenesis: Studies on the Mechanism of Action of Angiotensin and Electrolytes
}

\author{
Takao Saruta, Robert Cook, and Norman M. Kaplan \\ From the Department of Internal Medicine, The University of Texas \\ Southwestern Medical School, Dallas, Texas 75235
}

A в S T R A C T The effects of adrenocorticotropin (ACTH), angiotensins I and II, increased potassium, and decreased sodium concentrations upon steroid synthesis were examined by incubation of beef adrenal tissue slices.

Angiotensin II shared with ACTH the need for calcium and an inhibition of its effect in the presence of puromycin but differed in not stimulating cyclic adenosine monophosphate (AMP). Angiotensin I was effective in steroidogenesis. The stimulation of aldosterone synthesis by increased potassium concentration was accompanied by an increased level of cyclic AMP and was inhibited in the presence of puromycin. Decreased sodium concentration stimulated aldosterone synthesis but, alone of these stimuli, simultaneously decreased corticosterone levels.

It therefore appears that ACTH and potassium stimulate steroidogenesis at an early step in the biosynthetic pathway through the activation of cyclic AMP, whereas the effect of angiotensins I and II involve another mechanism and decreased sodium concentration affects a later step in steroidogenesis.

\section{INTRODUCTION}

The control of aldosterone secretion involves at least three mechanisms : adrenocorticotropin (ACTH), angiotensin, and potassium. In addition, other hormones and electrolytes may be involved. Despite intensive research for over 15 years, considerable controversy remains concerning the relative importance of these various mechanisms and their possible interrelationships. Thus the role of the renin-angiotensin system has been ques-

This work was presented in part at the Southern Society for Clinical Investigation, 30 January 1971, and at the 53rd Meeting of the Endocrine Society, 25 June 1971.

Received for publication 12 November 1971 and in revised form 20 March 1972. tioned in large measure because the most popular experimental model, the rat, does not respond to this stimulus nearly as well as most higher species, including the hu$\operatorname{man}(1)$.

We have previously used an in vitro model, slices of beef adrenal cortex, to examine the effects of various stimuli upon steroid synthesis $(2,3)$. As with other in vitro models, effects could be demonstrated only with relatively large amounts of stimuli, amounts greater than "physiologic," in vivo. However the results were in keeping with the major findings in man and other higher species, including the relatively selective role of $\mathrm{ACTH}$ upon cortisol and of angiotensin and potassium upon aldosterone.

Additional studies have therefore been performed, looking first at the effects of ACTH in this model since considerable data are available on the mechanism by which it stimulates steroidogenesis (4). Second, since less is known about other stimuli, studies were directed at comparing the possible mechanisms of action of angiotensin and potassium with that of ACTH. Third, the effect of varying sodium concentrations were examined since the effect of concentration has been difficult to separate from that of volume during in vivo studies.

\section{METHODS}

Tissue preparation and incubation. As in the previous studies, $(2,3)$ the outer slices of 16-20 fresh beef adrenal glands were combined, cut into small pieces with scissors, and divided into 500-mg portions for incubation. In each study, 24-40 separate portions were incubated with at least 4 portions for each point in the experiment.

The tissues were preincubated for $1 \mathrm{hr}$ in Krebs-Ringer bicarbonate medium containing glucose at a concentration of $200 \mathrm{mg} / 100 \mathrm{ml}$ under $95 \% \quad \mathrm{O}_{2}-5 \% \quad \mathrm{CO}_{2}$ at $37^{\circ} \mathrm{C}$ with continuous, gentle shaking. In experiments with puromycin, it was added to the preincubation media. The media were replaced with $5 \mathrm{ml}$ of the same solution except where differing electrolyte concentrations were being examined. Appropriate stimulatory agents were added and incubation 
conducted for $2 \mathrm{hr}$ except in the experiments upon the conversion of angiotensin I to angiotensin II and in some of those upon cyclic AMP. Less variation in the steroid levels in the control vessels and somewhat less responsiveness to stimulation were noted in these studies than in those previously published $(2,3)$ possibly because the time from death of the animals to start of the incubations was more uniform but also about $15 \mathrm{~min}$ longer. The mean values and the per cent SD for the three steroids in all control 2-hr incubations were: aldosterone, $2.01 \mu \mathrm{g} / \mathrm{g}$ tissue with a $9.8 \% \mathrm{SD}$; corticosterone, $12.04 \mu \mathrm{g} / \mathrm{g}$ tissue with a $15.2 \%$ SD; and cortisol, $2.01 \mu \mathrm{g} / \mathrm{g}$ tissue with a $11.6 \% \mathrm{SD}$.

Stimulatory agents. Amounts of these stimulatory agents were at least 10 -fold greater than the lowest doses previously noted to produce significant effects (3), to ensure that suppression by other agents, e.g., puromycin, would be demonstrable. ACTH was a single batch of the porcine, aqueous product known to be biologically active on cortisol secretion in man. Angiotensin I and II were the synthetic asparagine-1, valine- 5 polypeptides. Varying concentrations of sodium, potassium, and calcium were obtained by using more or less of the stock solutions in preparing the KrebsRinger medium. Unless otherwise indicated, the concentrations in the medium, per liter, were: sodium, $142 \mathrm{mEq}$; potassium, $5.2 \mathrm{mEq}$; calcium, $5 \mathrm{mEq}$; and bicarbonate, $25 \mathrm{mEq}$.

Assay procedures. After incubation, the media were decanted and $1 \mathrm{ml}$ was analyzed for steroids by a doubleisotope derivative assay (5), using acetic- $\mathrm{H}^{3}$-anhydride with a SA of $25 \mu \mathrm{Ci} / \mu$ mole. The assay was modified only by the addition of known amounts of the appropriate $4^{14} \mathrm{C}$ ring-labeled steroids to each sample of medium as internal standards at the onset of the assay. In addition, two paper chromatographic separations were used before and two after oxidation of the tritium-labeled acetates of the different steroids.

Values are expressed as micrograms of steroid in the incubation medium/gram of tissue per total incubation. The mean and standard deviation of the values in each group of vessels were compared with those of the control specimens simultaneously incubated. Statistical evaluation was by Dunnett's test for multiple comparisons with a control (6).
Cyclic AMP assays were performed by a radioimmunoassay (7), validated by the complete inactivation of cyclic AMP, either released from tissue incubates or added to the media, by beef heart cyclic nucleotide phosphodiesterase (8). Replicate analyses varied less than $15 \%$. Only very low levels of cyclic AMP could be measured in homogenates of the adrenal tissue under various experimental conditions, so that only media were assayed in most experiments. Since the recovery from the media of cyclic AMP added to tissue incubates fell from $74 \%$ at $15 \mathrm{~min}$ to only $36 \%$ at $2 \mathrm{hr}$, an additional series of shorter incubations were done. None of the cyclic AMP added to the media could be measured in the homogenates of the tissues after either $15 \mathrm{~min}$ or $2 \mathrm{hr}$. After 15-min incubations, the tissue levels of cyclic AMP remained considerably below those in the media though the direction and degree of change under various experimental conditions paralleled those in the media.

In the experiments with angiotensin I, after the period of incubation, $0.1 \mathrm{ml}$ of EDTA, $2.6 \mathrm{~mm}$, and 8-hydroxyquinoline, $3.4 \mathrm{~mm}$, were added to inhibit the enzyme involved in the conversion of angiontensin I to angiotensin II and the angiotensinases present in the tissue. It was not possible to have these inhibitory agents present during the incubation period since neither angiotensin I nor angiotensin II were active in their presence, presumably because of the binding of calcium and other needed cofactors. The two angiotensins were separated by the method of Boucher (9). $1 \mathrm{ml}$ of medium was vigorously shaken with $8 \mathrm{ml}$ of Dowex resin $50 \mathrm{~W}-\mathrm{X} 8$ for $15 \mathrm{~min}$ and the mixture transferred to columns containing $2 \mathrm{ml}$ of the resin. Angiotensin II was eluted with $4 \mathrm{~m}$ pyridine and then angiotensin I was eluted with $0.2 \mathrm{M} \mathrm{NH} \mathrm{NH}_{4} \mathrm{OH}$. The eluates were lyophlized, redissolved in $20 \%$ ethanol, and assayed by bioassay (10) and radioimmunoassays for angiotensin I (II) and angiotensin II (12).

The ability of this technique to recover and separate the two angiotensins was checked in three experiments with a solution containing $1200 \mathrm{ng}$ of each. The initial eluate contained $69.1 \%$ of the angiotensin II and $13.5 \%$ of the angiotensin I. The second eluate contained $72.5 \%$ of the angiotensin I and $8.1 \%$ of the angiotensin II. The over-all recovery of angiotensin I was $86 \%$ and of angiotensin II

TABLE I

Effect of Various Stimuli upon Aldosterone and Cyclic AMP Levels in Media of Beef Adrenal Slice Incubates

\begin{tabular}{|c|c|c|c|c|c|c|c|c|c|}
\hline \multirow{2}{*}{$\begin{array}{c}\text { Experi- } \\
\text { ment }\end{array}$} & \multirow[b]{2}{*}{ Stimulant } & \multicolumn{2}{|c|}{ Aldosterone } & \multicolumn{2}{|c|}{ Corticosterone } & \multicolumn{2}{|c|}{ Cortisol } & \multicolumn{2}{|c|}{ Cyclic AMP } \\
\hline & & Mean & SD & Mean & SD & Mean & SD & Mean & SD \\
\hline \multirow{6}{*}{1} & & \multicolumn{4}{|c|}{$\mu \mathrm{g} / \mathrm{g}$ tissue per incubation } & \multicolumn{4}{|c|}{ pmoles/g tissue per incubation } \\
\hline & $2 \mathrm{hr}$ incubation & & & & & & & & \\
\hline & Control & 2.08 & 0.20 & 10.24 & 1.05 & 1.89 & 0.17 & 57.5 & 5.2 \\
\hline & ACTH, $2 \mathrm{U}$ & 3.21 & $0.28 *$ & 17.38 & 1.60 & 4.08 & 0.57 & 105.6 & 12.5 \\
\hline & Angiotensin, $20 \mu \mathrm{g}$ & 5.57 & 0.63 & 23.75 & 2.50 & 3.34 & 0.28 & 54.3 & 4.0 \\
\hline & Potassium, $9.2 \mathrm{mEq} /$ liter & 4.76 & 0.42 & 21.87 & 2.35 & 1.98 & 0.12 & 91.3 & 11.0 \\
\hline \multirow[t]{5}{*}{2} & 15 min incubation & & & & & & & & \\
\hline & Control & 1.02 & 0.08 & 4.44 & 0.40 & 1.10 & 0.06 & 81.2 & 5.9 \\
\hline & ACTH, $2 \mathrm{U}$ & 1.76 & 0.13 & 6.36 & 0.26 & 2.23 & 0.11 & 233.0 & 20.2 \\
\hline & Angiotensin, $20 \mu \mathrm{g}$ & 2.11 & 0.14 & 7.65 & 0.54 & 1.51 & 0.10 & 85.5 & 6.1 \\
\hline & Potassium, $9.2 \mathrm{mEq} /$ liter & 1.98 & 0.11 & 6.70 & 0.35 & 1.17 & 0.09 & 185.3 & 14.7 \\
\hline
\end{tabular}

* Results in italics differ statistically from the control level with $P$ value less than 0.05 . 
was $77.2 \%$. The recoveries of both varied less than $5 \%$ between the three experiments.

\section{RESULTS}

In each experiment reported, the adrenal tissue was responsive, showing at least a $25 \%$ increase above control in the synthesis of aldosterone with angiotensin II, 10 $\mu \mathrm{g} / \mathrm{g}$ tissue, and in the synthesis of cortisol with $\mathrm{ACTH}$, $1 \mathrm{U} / \mathrm{g}$ tissue. In these studies only media were analyzed since, as noted before (2), changes in steroid levels within the tissue were found to be virtually parallel to those in the media.

Certain aspects of the action of $\mathrm{ACTH}$ in vitro were confirmed in this model to validate those studies in which comparisons to the action of ACTH were made: (a) $\mathrm{ACTH}$ had no effect upon steroidogenesis in the absence of calcium in the incubation medium. (b) As shown in Table I, cyclic AMP levels increased significantly in experiments wherein ACTH, $2 \mathrm{U} / \mathrm{g}$ tissue, stimulated steroid biosynthesis. (c) The action of ACTH upon steroid synthesis was inhibited in the presence of puromycin, $10^{-8}$. By itself, puromycin decreased the level of steroidogenesis from that observed in the control vessels.

\section{Studies with angiotensin}

Angiotensin I vs. angiotensin II. Initially, experiments were performed with microgram quantities of both polypeptides added to $500-\mathrm{mg}$ portions of tissue for 2-hr incubations. However, more than $60 \%$ of each peptide was destroyed during that interval, and of that remaining, $70 \%$ of the angiotensin I was converted into angiotensin II. Therefore incubations were performed for $15 \mathrm{~min}$ during which an average of $32 \%$ of the peptides were destroyed and $27 \%$ of the remaining angiotensin I had been converted into angiotensin II.

As shown in Table II, the effects of $1 \mu \mathrm{g}$ of angiotensins I and II were compared in two experiments. In experiment 3 , similar effects were observed with both polypeptides. Since the apparent effect of the angiotensin I may have been produced by its one-third conversion to angiotensin II, experiment 4 was performed using an equivalent amount of angiotensin II as that converted from angiotensin I. As shown in Table II, no effect was observed with $210 \mathrm{ng}$ of angiotensin II during this incubation. Of the original $1080 \mathrm{ng}$ of angiotensin I, an even smaller quantity (122 $\mathrm{ng}$ ) had been converted to angiotensin II. Therefore the effect observed with the angiotensin I could not be attributed simply to that portion converted to angiotensin II.

Need for calcium. In the absence of calcium, angiotensin (20 $\mu \mathrm{g} / \mathrm{g}$ tissue) did not significantly stimulate steroid synthesis.

Effect on cyclic $A M P$. As shown in Table I, cyclic AMP levels were unchanged in both experiments wherein
TABLE II

The Effects of Angiotensins $I$ and $I I$ ( $A-I$ and $A-I I$ ) upon Steroid Synthesis in Beef Adrenal Tissue

\begin{tabular}{|c|c|c|c|c|c|c|c|c|c|c|}
\hline \multirow{2}{*}{$\begin{array}{l}\text { Ex- } \\
\text { peri- } \\
\text { ment }\end{array}$} & \multicolumn{2}{|c|}{ Added } & \multicolumn{2}{|c|}{ Recovered } & \multicolumn{2}{|c|}{ Aldosterone } & \multicolumn{2}{|c|}{$\begin{array}{l}\text { Corti- } \\
\text { costerone }\end{array}$} & \multicolumn{2}{|c|}{ Cortisol } \\
\hline & A-I & A-II & A-I & A-II & Mean & SD & Mean & SD & Mean & SD \\
\hline & \multicolumn{2}{|c|}{$n g$} & \multicolumn{2}{|c|}{$n g$} & & & \multicolumn{2}{|c|}{$\begin{array}{c}u g / g \text { tissue per } \\
15 \text { min }\end{array}$} & & \\
\hline \multirow[t]{3}{*}{3} & 一 & - & - & 一 & 0.99 & 0.13 & 11.16 & 1.12 & 1.54 & 0.07 \\
\hline & 1050 & 一 & 540 & 171 & 1.59 & $0.21 *$ & 12.86 & 0.85 & 1.93 & 0.16 \\
\hline & - & 1100 & - & 748 & 1.58 & 0.18 & 12.55 & 0.73 & 2.00 & 0.23 \\
\hline \multirow[t]{4}{*}{4} & 一 & - & - & - & 1.74 & 0.21 & 7.52 & 0.69 & 2.46 & 0.21 \\
\hline & 1080 & - & 610 & 122 & 2.79 & 0.35 & 12.05 & 0.88 & 2.56 & 0.27 \\
\hline & - & 210 & - & 137 & 1.86 & 0.26 & 7.60 & 0.45 & 2.33 & 0.40 \\
\hline & - & 1050 & - & 720 & 2.95 & 0.31 & 11.57 & 1.01 & 2.68 & 0.39 \\
\hline
\end{tabular}

* Results in italics differ statistically from the control level with $P$ value less than 0.05 .

angiotensin exerted a significant effect $(P<0.01)$ upon aldosterone synthesis. Similar results were noted in two additional studies, one a $15 \mathrm{~min}$ incubation, the other a $2 \mathrm{hr}$ incubation.

Puromycin. In experiment 5 of Fig. 1, angiotensin (20 $\mu \mathrm{g} / \mathrm{g}$ tissue) and in three other experiments with both 2 and $20 \mu \mathrm{g}$ angiotensin, puromycin $10^{-8}$, and $10^{-4} \mathrm{M}$ lowered steroid synthesis and completely inhibited the effect of angiotensin II upon steroidogenesis.

\section{Studies with increased potassium}

Effect on cyclic AMP. As shown in Table I, cyclic AMP levels were significantly elevated in both experiments wherein an increased potassium concentration

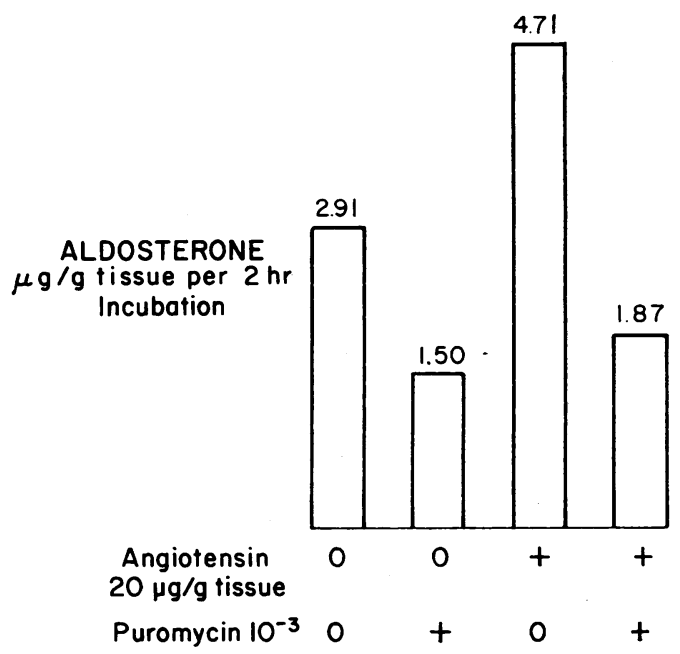

FIGURE 1 The effects of angiotensin and puromycin alone and in combination upon aldosterone synthesis (experiment $5)$. 


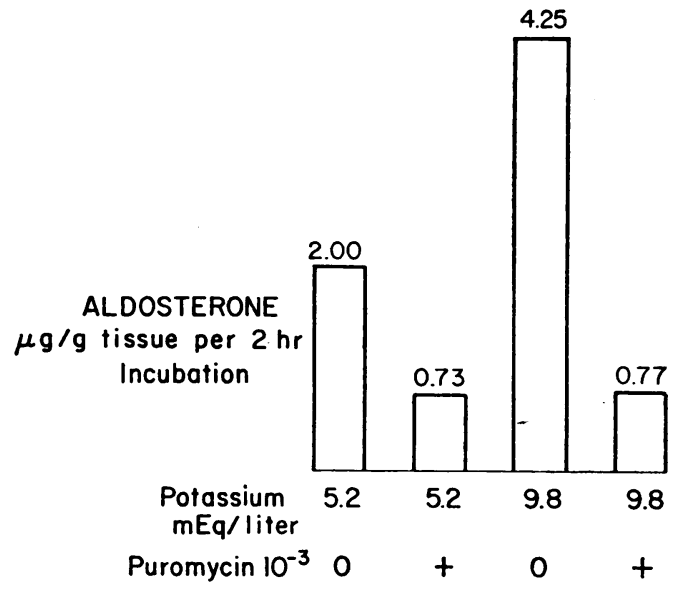

FIgURE 2 The effects of increased potassium and puromycin alone and in combination upon aldosterone synthesis.

stimulated aldosterone biosynthesis. In these studies, cortisol was unaffected by the increased potassium.

Puromycin. In the experiment shown in Fig. 2, puromycin $10^{-8}$ lowered steroid synthesis and completely inhibited the stimulation of aldosterone synthesis produced by an increased potassium concentration. Similar inhibition of both aldosterone and corticosterone was observed in three other experiments with puromycin $10^{-4} \mathrm{M}$ and potassium concentrations of $8.3,9.0$, and $9.3 \mathrm{mEq} /$ liter.

\section{Studies with decreased sodium}

Fig. 3 portrays the effect of a sodium concentration of $112 \mathrm{mEq} /$ liter upon aldosterone and corticosterone release as compared with the effects of ACTH, angiotensin, and increased potassium. In that experiment and in the experiment shown in Table III, aldosterone synthesis was stimulated by the lowered sodium concentration but, in contrast to the effects of the other stimuli, corticosterone levels were simultaneously decreased. Rather marked decreases in sodium concentration were required to stimulate aldosterone synthesis in this in

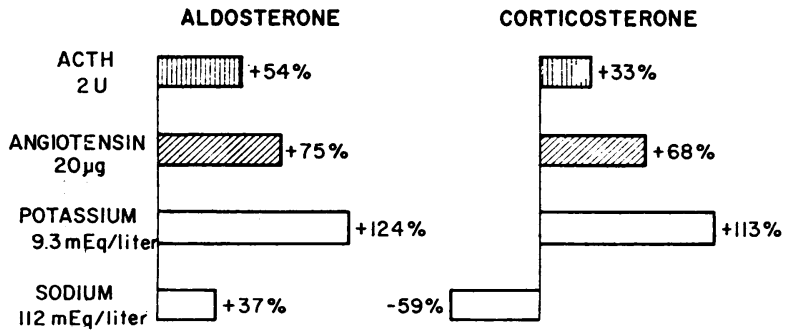

FIGURE 3 The effects of $\mathrm{ACTH}$, angiotensin II, increased potassium, or decreased sodium concentrations upon aldosterone and corticosterone synthesis in beef adrenal tissue. The values are per cent change from control vessels.
TABLE III

The Effects of Varying Sodium Concentration and Osmolality upon Steroid Synthesis in Beef Adrenal Tissue

\begin{tabular}{|c|c|c|c|c|c|c|c|}
\hline \multirow{2}{*}{\multicolumn{2}{|c|}{$\begin{array}{l}\text { Sodium } \\
\text { concen- } \\
\text { tration } \mathbf{3} \text { Osmolality }\end{array}$}} & \multicolumn{2}{|c|}{ Aldosterone } & \multicolumn{2}{|c|}{ Corticosterone } & \multicolumn{2}{|c|}{ Cortisol } \\
\hline & & Mean & ISD & Mean & SD & Mean & SD \\
\hline $\begin{array}{l}m E q / \\
\text { liter }\end{array}$ & $\begin{array}{c}\text { mOsm/ } \\
\text { liter }\end{array}$ & \multicolumn{6}{|c|}{$\begin{array}{c}\mu g / g \text { tissue per } \\
2 \mathrm{hr}\end{array}$} \\
\hline 160 & 297 & 1.63 & 0.08 & 23.15 & 2.94 & 3.37 & 0.40 \\
\hline 142 & 309 & 1.59 & 0.21 & 20.64 & 1.83 & 2.94 & 0.36 \\
\hline 142 & 276 & 1.64 & 0.10 & 22.49 & 1.99 & 3.44 & 0.51 \\
\hline 123 & 276 & 1.98 & $0.24^{*}$ & 19.28 & $0.57(-) \ddagger$ & 3.69 & 0.32 \\
\hline 100 & 277 & 2.60 & 0.06 & 17.56 & $0.67(-)$ & 4.37 & 0.94 \\
\hline 100 & 250 & 2.48 & 0.15 & 16.96 & $1.21(-)$ & 3.75 & 0.61 \\
\hline
\end{tabular}

* Results in italics differ statistically from the control level (third line) with $P$ value less than 0.05 .

$\ddagger$ Values with $(-)$ are significantly less than the control level with $P$ value less than 0.05 .

vitro preparation. In the experiment shown in Table III, the osmolality of the media was maintained at $276 \mathrm{mOsm}$ by the addition of appropriate amounts of mannitol. No effect of varying osmolality per se was noted in that steroid synthesis was unchanged in the tissues exposed to an osmolality of 250 or 309 when compared with that observed in vessels with the same sodium concentrations but osmolalities of 276 .

\section{DISCUSSION}

This in vitro model provides a means to examine, individually, various factors affecting adrenal steroidogenesis. These results should be applied to human physiology with caution but they appear to be more applicable than many studies on lower species, particularly the rat. Rat adrenal tissue does not produce cortisol, the major glucocorticoid in the human and most higher species. Other major differences between the rat and other species have been noted, in particular the poor response of the rat to angiotensin (1). Our previous studies with beef adrenal tissue have shown a relative selectivity of ACTH upon cortisol synthesis and of angiotensin and potassium upon aldosterone synthesis ( 3 ) closely paralleling the results of in vivo studies in the sheep (13), the monkey (14), and man (15-18). However, differences have also been observed between other experimental models and the human (18) so that caution is advised in application of all such studies to human physiology (19). Moreover, the intact adrenal is affected by various factors in complex interactions. To isolate one factor is highly artificial, but necessary to demonstrate basic mechanisms of action.

A model for the action of ACTH has been proposed. The mechanism is thought to first involve the binding of ACTH to receptor sites on the plasma membrane. By a process which requires calcium (20), the bound ACTH stimulates adenyl cyclase in the plasma membrane, which 
in turn increases the formation of cyclic AMP. This nucleotide stimulates steroidogenesis apparently by increasing the synthesis of a protein needed in the conversion of cholesterol to pregnenolone within the mitochondrion. Recent work has shown that cyclic AMP may act by releasing a phosphokinase needed for protein synthesis from a receptor which keeps the phosphokinase from being active (21).

The effect of an inhibitor of protein synthesis, puromycin, has been used to construct this model of ACTH action. Puromycin, which inhibits the incorporation of amino acids into protein via translation of messenger RNA at the ribosome prevents the action of ACTH and cyclic AMP (22). Therefore the action of ACTH and cyclic AMP is thought to involve the synthesis of a specific regulator protein with a presumably short time span of action. However, in common with the results noted by others (23), we observed a decrease in steroid synthesis in nonstimulated tissue in the presence of puromycin. Therefore it would be more appropriate to say that puromycin, an inhibitor of protein synthesis, blocks steroidogenesis, whether hormone-stimulated or not. The effect of puromycin cannot then be used as direct proof that ACTH stimulation of steroidogenesis involves protein synthesis.

Having confirmed the postulated mechanism of action of ACTH in this in vitro model, we then examined the action of angiotensin. Though angiotensin shared certain characteristics with ACTH as regards the need for calcium and the inhibition of its effect in the presence of puromycin, a distinct difference was noted in that angiotensin did not increase cyclic AMP levels.

The failure of angiotensin II to stimulate adenyl cyclase has been previously noted in two studies, one upon bovine adrenal tissue fractions being examined for binding activity (24), the other upon particles of normal and cancerous rat adrenal tissue (25).

Whether binding is required for the action of angiotensin, as it is for ACTH, is unknown, but angiotensin has been shown to bind to various tissues, including bovine adrenal cortical slices (26). As with ACTH (27) its binding was not inhibited in the absence of calcium. However, its action upon steroidogenesis does appear to require calcium.

These studies on the binding of angiotensin are relevant in another manner to the results of our work. Beef adrenal cortex showed a greater specific binding of angiotensin I than of angiotensin II (24). We have found a steroidogenic effect of angiotensin I not attributable to its conversion to angiotensin II. There are no known differences in the physiologic role of the two polypeptides but it is of interest that, despite the virtual ubiquity of the enzyme which converts I into II, plasma levels of I are considerably higher than II (28). Since angiotensin
I does bind itself to the adrenal and since it exerts a steroidogenic effect, perhaps it is mediator of the reninangiotensin system upon the control of aldosterone synthesis.

Potassium appears to be a prime modulator of aldosterone synthesis (29) and may be the intermediate in the action of various stimuli (30). As in vivo (13), potassium has a selective effect upon aldosterone in vitro. Our studies have shown that its action is accompanied by an increase in cyclic AMP and is blocked in the presence of puromycin. We have previously demonstrated a potentiation by potassium of the effect of angiotensin in vitro (3). In earlier studies with bovine adrenal slices (31), potassium was found not to increase cyclic AMP but the slices were prepared after removing the capsule which would remove most if not all of the zona glomerulosa wherein aldosterone is formed. The absence of an effect of potassium on cortisol synthesis is in keeping with its previously reported failure to increase cyclic AMP levels within the zona fasciculata (31). Our studies included the capsule (outer slice) and potassium was shown to stimulate both aldosterone synthesis and cyclic AMP levels. Potassium has been reported to increase cyclic AMP levels in other tissues (32) and to enhance the response of adenyl cyclase in fat cells to ACTH (33).

The effects of sodium concentration per se have been difficult to separate from the effects of changes in plasma or extracellular fluid volume in most in vivo studies. Aldosterone is increased when fluid volume is decreased, presumably through the renin-angiotensin system, which acts early in the biosynthetic pathway and increases corticosterone synthesis as well (18). The stimulation of aldosterone synthesis by a low sodium concentration noted in these in vitro studies was unique in being accompanied by a decrease in the levels of corticosterone. This observation is in keeping with other studies supporting an effect of sodium depletion upon the conversion of corticosterone to aldosterone in addition to the expected effect of angiotensin earlier in biosynthesis (34). Studies on sheep have shown an increased conversion of corticosterone to aldosterone with modest sodium depletion but a return to the expected rate of conversion with more severe depletion (35). Even though plasma sodium concentration is not decreased initially with salt depletion, the cellular sodium content is reduced much earlier (36). An increased conversion of corticosterone to aldosterone has been demonstrated in the mitochondria of adrenals from salt-depleted rats (37) and a mechanism by which varying sodium concentration may alter the biosynthetic sequence between corticosterone and aldosterone has been postulated (38). Though these two mechanisms, volume affecting the entire biosynthetic pathway early via angiotensin and concentration affecting 
a later step, appear to fit most experimental data, the control of aldosterone secretion in sodium-deficient sheep appears to involve even other, unrecognized factors (39).

The major findings of the in vitro studies here reported are in keeping with most in vivo experiments. Obviously the intact organism can bring a number of factors into play so that "pure" effects as seen in vitro would not be expected. However, the ability to isolate stimuli has provided evidence of a basic difference in the mechanism of action of the angiotensin system and other factors affecting adrenal steroidogenesis.

\section{ACKNOWLEDGMENTS}

This work was supported by grants from the U. S. Public Health Service (5 RO1 HE 11639-03) and the Dallas and Texas Heart Associations.

\section{REFERENCES}

1. Marieb, N. J., and P. J. Mulrow. 1965. Role of the renin-angiotensin system in the regulation of aldosterone secretion in the rat. Endocrinology. 76: 657.

2. Kaplan, N. M., and F. C. Bartter. 1962. The effect of $\mathrm{ACTH}$, renin, angiotensin II, and various precursors on biosynthesis of aldosterone by adrenal slices. J. Clin. Invest. $41: 715$.

3. Kaplan, N. M. 1965. The biosynthesis of adrenal steroids: effects of angiotensin II, adrenocorticotropin, and potassium. J. Clin. Invest. 44: 2029.

4. Garren, L. D., W. W. Davis, G. N. Gill, H. L. Moses, R. L. Ney, and R. M. Crocco. 1969. Studies on the mode of action of ACTH. In Progress in Endocrinology. Carlos Gual, editor. Excerpta Medica Foundation, Publishers, Amsterdam. 102.

5. Kliman, B., and R. E. Peterson. 1960. Double isotope derivative assay of aldosterone in biological extracts. J. Biol. Chem. 235 : 1639.

6. Dunnett, C. W. 1964. New tables for multiple comparisons with a control. Biometrics. 20: 482.

7. Steiner, A. L., D. M. Kipnis, R. Utiger, and C. Parker. 1969. Radioimmunoassay for the measurement of adenosine $3^{\prime}, 5^{\prime}$-cyclic phosphate. Proc. Natl. Acad. Sci. U. S. A. $64: 367$.

8. Kelly, L. A., and S. B. Koritz. 1971. Bovine adrenal cortical adenyl cyclase and its stimulation by adrenocorticotropic hormone and NaF. Biochim. Biophys. Acta. 237 : 141.

9. Boucher, R., H. Kurihara, C. Grise, and J. Genest. 1970. Measurement of plasma angiotensin I converting

10. Pickens, P. T., M. Bumpus, A. M. Lloyd, R. R. Smeby, enzyme activity. Circ. Res. Suppl. 26: 1.

and I. H. Page. 1965. Measurement of renin activity in human plasma. Circ. Res. 17: 438.

11. Haber, E., T. Koerner, L. B. Page, B. Kliman, and A. Purnode. 1969. Application of a radioimmunoassay for angiotensin $I$ to the physiologic measurements of plasma renin activity in normal human subject. J. Clin. Endocrinol. Metab. 29: 1349.

12. Gocke, D. J., J. Gerten, J. M. Sherwood, and J. H. Laragh. 1969. Physiological and pathological variations of plasma angiotensin II in man. Correlation with renin activity and sodium balance. Circ. Res. Suppl. 24: 1.
13. Blaire-West, J. R., J. P. Coghlan, D. A. Denton, B. A. Scoggins, E. M. Wintour, and R. D Wright 1970. The onset of effect of ACTH, angiotensin II and raised plasma potassium concentration on the adrenal cortex. Steroids. $15: 433$.

14. Scurry, M. T., and J. Bruton. 1968. Steroid hormone production following adrenal stimulation in the rhesus monkey. Acta Endocrinol. 58: 637.

15. Luetscher, J. A., Jr., and R. H. Curtis. 1955. Aldosterone: observations on the regulation of sodium and potassium balance. Ann. Intern. Med. 43: 658 .

16. Liddle, G. W., L. E. Duncan, Jr., and F. C. Bartter. 1956. Dual mechanism regulating adrenocortical function in man. Am. J. Med. 21: 380.

17. Laragh, J. H., M. Angers, W. G. Kelly, and S. Lieberman. 1960. The effect of epinephrine, norepinephrine, angiotensin II, and others on the secretory rate of aldosterone in man. J. Am. Med. Assoc. 174: 234.

18. Bledsoe, T., D. P. Island, and G. W. Liddle. 1966. Studies of the mechanism through which sodium depletion increases aldosterone biosynthesis in man. $J$. Clin. Invest. $45: 524$.

19. Müller, J. 1971. Regulation of aldosterone biosynthesis. Monographs on Endocrinology. Springer-Verlag, New York. 5: 103.

20. Bär, H. P., and O. Hechter. 1969. Adenyl cyclase and hormone action. III. Calcium requirement for ACTH stimulation of adenyl cyclase. Biochem. Biophys. Res. Commun. 35 : 681 .

21. Gill, G. N., and L. D. Garren. 1971. The function of the c-AMP receptor protein. Program Abstracts of the Program of the 53rd Endocrine Society. A-47.

22. Ferguson, J. J., Jr. 1963. Protein synthesis and adrenocorticotropin responsiveness. J. Biol. Chem. 238: 2754

23. Kittinger, G. W. 1964. Puromycin inhibition of in vitro cortical hormone production by the rat adrenal gland. Steroids. 4 : 539.

24. Goodfriend, T. L., and S. Y. Lin. 1970. Receptors for angiotensin I and II. Circ. Res. Suppl. 26: 1.

25. Schorr, I., and R. L. Ney. 1971. Abnormal hormone responses of an adrenocortical cancer adenyl cyclase. J. Clin. Invest. 50: 1295.

26. Lin, S.-Y., and T. L. Goodfriend. 1970. Angiotensin receptors. Am. J. Physiol. 218: 1319.

27. Lefkowitz, R. J., J. Roth, and I. Pastan. 1970. Effects of calcium on ACTH stimulation of the adrenal: separation of hormone binding from adenyl cyclase activation. Nature (Lond.). 228: 864.

28. Boyd, G. W., A. E. Fitz, A. R. Adamson, and W. S. Peart. 1969. Radioimmunoassay determination of plasmarenin activity. Lancet. 1: 213.

29. Cannon, P. J., R. P. Ames, and J. H. Laragh. 1966. Relation between potassium balance and aldosterone secretion in normal subjects and in patients with hypertensive or renal tubular disease. J. Clin. Invest. 45: 865.

30. Baumber, J. S., J. O. Davis, J. A. Johnson, and R. T. Witty. 1971. Increased adrenocortical potassium in association with increased biosynthesis of aldosterone. Am. J. Physiol. 220: 1094.

31. Haynes, R. C., Jr. 1958. The activation of adrenal phosphorylase by the adrenocorticotropic hormone. $J$. Biol. Chem. 233: 1220.

32. Rasmussen, H., and A. Tenenhouse. 1968. Cyclic adenosine monophosphate, $\mathrm{Ca}^{++}$, and membranes. Proc. Natl. Acad. Sci.U. S. A. 59: 1364.

33. Birnbaumer, L., S. L. Pohl, and M. Rodbell. 1969. 
Adenyl cyclase in fat cells. I. Properties and the effects of adrenocorticotropin and fluoride. J. Biol. Chem. 244: 3468.

34. Davis, W. W., L. R. Burwell, A. G. T. Casper, and F. C. Bartter. 1968. Sites of action of sodium depletion on aldosterone biosynthesis in the dog. J. Clin. Invest. 47: 1425.

35. Blair-West, J. R., A. Brodie, J. P. Coghlan, D. A. Denton, C. Flood, J. R. Goding, B. A. Scoggins, J. F. Tait, S. A. S. Tait, E. M. Wintour, and R. D. Wright. 1970. Studies on the biosynthesis of aldosterone using the sheep adrenal transplant: effect of sodium depletion on the conversion of corticosterone to aldosterone. $J$. Endocrinol. 46 : 453.

36. Davis, J. O., P. F. Binnion, T. C. Brown, and C. I.
Johnston. 1966. Mechanisnis involved in the hypersecretion of aldosterone during sodium depletion. Circ. Res. Suppl. 18: 1 .

37. Marusic, E. T., and P. J. Mulrow. 1967. Stimulation of aldosterone biosynthesis in adrenal mitochondria by sodium depletion. J. Clin. Invest. 46: 2101.

38. Sharma, D. Cited in W. F. Ganong, E. G. Biglieri, and P. J. Mulrow. 1966. Mechanisms regulating adrenocortical secretion of aldosterone and glucocorticoids. Recent Prog. Horm. Res. 22: 425.

39. Blair-West, J. R., J. P. Coghlan, D. A. Denton; J. W. Funder, B. A. Scoggins, and R. D. Wright. 1971. The effect of adrenal arterial infusion of hypertonic $\mathrm{Na}$ $\mathrm{HCO}_{8}$ solution on aldosterone secretion in sodium deficient sheep. Acta Endocrinol. 66: 448. 